\title{
Advancing tobacco control research in Ghana: findings from a meeting with key stakeholders
}

\author{
Arti Singh ${ }^{1}$, Fiona Dobbie ${ }^{2}$, Divine D Logo ${ }^{3}$, Fiona Davidson², Rob Ralston², Patricia A Wirenkyi ${ }^{1}$, David Doku ${ }^{4}$, John \\ Britton $^{5}$, Linda Bauld ${ }^{2}$, Ellis Owusu-Dabo ${ }^{1}$ \\ ${ }^{1}$ School of Public Health, KNUST, Ghana, 2 Usher Institute and SPECTRUM Consortium, University of Edinburgh, UK, ${ }^{3}$ Research and Development \\ Division, Ghana Health Service, Accra, Ghana, ${ }^{4}$ Directorate of Research, Innovation and Consultancy, University of Cape Coast, Ghana, 5 University of \\ Nottingham, UK \\ Keywords: stakeholder, tobacco control, tobacco, policy, ghana
}

https://doi.org/10.29392/001c.22232

\section{Journal of Global Health Reports}

Vol. 5, 2021

\begin{abstract}
Prevalence of non-communicable diseases (NCDs) is growing globally, with the greatest increase in NCD deaths expected to occur in sub-Saharan Africa (SSA) over the next five to 15 years. Tobacco use is implicated in all leading NCDs, and is one of the biggest global public health threats. Despite the projected increase in tobacco-related NCD deaths in low- and Middle-income countries (LMICs), research on tobacco control policy and implementation in SSA and more specifically, Ghana, is a low priority. To address these challenges, the School of Public Health (KNUST, Ghana) with support from the Tobacco Control Capacity Program (TCCP) funded by the Global Challenges Research Fund (GCRF) organized a 1-day stakeholder's meeting to discuss the advancement of tobacco control research in Ghana. The aim was to propose the way forward for strengthening applied research that can inform the development of health policies and programs focused on tobacco control. Participants were drawn from academia, research and health institutions, civil society and non-governmental organisations. In this meeting overview, we present the key themes that emerged from the meeting and some strategies for advancing tobacco control research in Ghana and beyond. Directions for future research agenda include building institutional research capacity, strengthening stakeholder and public engagement on tobacco control, need for more local and comprehensive data and research, improve sustainable funding of comprehensive programs on tobacco control in Ghana and social and behavior change communication on tobacco use.
\end{abstract}

Low and middle-income countries (LMICs) are disproportionately affected by the rise in prevalence of non-communicable diseases (NCDs). Up to three-quarters of deaths related to NCDs occur in LMICs. ${ }^{1}$ Tobacco use kills up to half of its users and is a major barrier to sustainable development, as it impedes progress towards the social, economic and environmental goals in the 2030 Agenda for Sustainable Development. ${ }^{2}$ Reducing tobacco use is, therefore, key to reducing the burden of NCDs. ${ }^{3}$ While tobacco epidemic has plateaued and is declining in many higher-income countries (HICs), it is accelerating in LMICs including sub-Saharan Africa (SSA). ${ }^{4}$ This makes the advancement of robust tobacco control measures and monitoring of their impact a public health priority for LIMCs.

The World Health Organization's Framework Convention on Tobacco Control (WHO FCTC), compels its 181 signatory countries, many of which are in LMICs, to meet minimum standards in tobacco control provisions, offering a powerful lever for tobacco control efforts worldwide. ${ }^{5}$ However, tobacco control has often been a lower priority compared to other health challenges in LMICs and SSA. ${ }^{6}$ Again, governments frequently lack data on tobacco-related health issues, tobacco industry interference remains high, and the capacity of tobacco control advocates and policymakers to implement control measures is uneven. ${ }^{7}$

Ghana, a LMIC in West Africa, has less than $10 \%$ of its population smoking tobacco (table 1), with more than 5,000 people dying from tobacco-related disease every year. ${ }^{8}$ According to the Ghana 2017 Global Youth Tobacco Survey (GYTS), $8.9 \%$ of boys and $8.2 \%$ (table 1) of girls currently use any form of tobacco products. ${ }^{9}$ Although cigarettes remain the more popular form of tobacco use, other forms of tobacco products such as shisha are becoming common particularly with adolescents. ${ }^{10}$ Regional trends in Ghana continue to show high prevalence from the northern part of the country - 31.2\%, 22.5\% and 7.9\% in the Upper East, Northern and Upper West regions respectively. ${ }^{11}$ The SSA region including Ghana is particularly vulnerable due to the its weak tobacco laws, and is expected to face the largest growth of tobacco consumption in the world. ${ }^{12}$ The changing determinants of tobacco use in SSA include: rapid increase in population; increase in disposable income; increased exposure to tobacco and second-hand smoke resulting from rapid urbanization; aggressive marketing of tobacco; and insufficient tobacco control policies.

While there is strong evidence on the effectiveness of tobacco control interventions from many high-income countries, this is lacking in LMICs including SSA. This can be at- 
Table 1. Findings from the DHS and GYTS in Ghana

\begin{tabular}{|l|l|l|l|}
\hline \multicolumn{2}{|l|}{ DHS } & GYTS \\
\hline Year (N) & $\begin{array}{l}\text { Tobacco use prevalence \% (male/ } \\
\text { female) }\end{array}$ & Year (N) & $\begin{array}{l}\text { Tobacco use among 13-15 years (males/ } \\
\text { females) }\end{array}$ \\
\hline $2003(10505)$ & $8.8 / 0.1$ & $2000(1088)$ & $16.2 / 17.4$ \\
\hline $2008(11913)$ & $7.0 / 0.4$ & $2006(5185)$ & $11.6 / 10.9$ \\
\hline $2014(11835)$ & $4.8 / 0.1$ & $2009(4171)$ & $14.1 / 10.6$ \\
\hline & & $2017(5664)$ & $8.8 / 8.1$ \\
\hline
\end{tabular}

tributed to a lack of resources due to competing priorities such as: malaria and HIV; lack of commitment from donors in funding research and developing research capacity; lack of awareness of policy makers; tobacco industry interference; and insufficient human research capacity to plan and implement research resulting in lower tobacco control policy implementation in the African region including SSA.

To help address these gaps, the Tobacco Control Capacity Programme (TCCP) (https://ukctas.net/GCRF-TCCP.html), a programme funded by UK Research and Innovation as part of the Global Challenges Research Fund (GCRF) aims to support research institutions in LMICs to develop policy relevant research in tobacco control in addition to developing research capacity in LMICs. ${ }^{13}$ It involves UK academics in five Universities along with research organisations in Bangladesh, Ethiopia, The Gambia, Ghana, India, South Africa and Uganda. The programme aims to invest in wider stakeholder engagement to identify pathways to impact and future options for the sustainability of the programme (linkages, collaboration and sustainability). Here we present a meeting overview on the key themes that emerged from a stakeholders meeting held in one of the TCCP country sites (Ghana) in 2018 and recommendations for addressing the gaps and advancing tobacco control research in SSA.

\section{MEETING OVERVIEW}

A one-day stakeholder meeting was organised by the School of Public Health (KNUST) in Kumasi, Ghana on $5^{\text {th }}$ September 2018. The aim of this meeting was to provide a platform for researchers and key stakeholders to deliberate on the key research gaps in tobacco control research, with special focus on country-specific priority areas in order to make recommendations on how to bridge the gap between research, policy and practice.

Meeting objectives were to:

1. Engage local government authorities, non-governmental organizations (NGOs), civil society organizations (CSOs) and other key stakeholders involved in tobacco control in Ghana.

2. Identify the current policy situation and gaps, key current discussions and future milestones of decision makers in tobacco control in Ghana.

3. Increase linkage and collaboration and identify steps for on-going stakeholder engagement as part of the GCRF objectives.

4. Present research ideas from the TCCP/GCRF to stake-

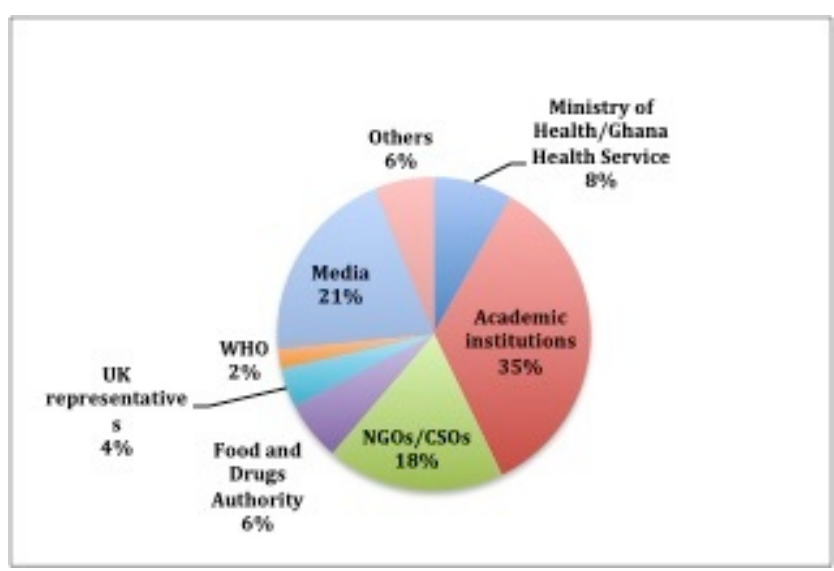

\section{Figure 1. Participant representation at the stakeholder's meeting.}

CSOs - Civil Society Organisation, NGOs - Non-governmental Organisations, WHO - World Health Organization.

holders and identify country-specific priority areas for future tobacco-related research in Ghana.

\section{STUDY PARTICIPANTS}

The stakeholder consultation survey yielded 39 responses (response rate to invitation $86.7 \%$ ). The largest proportion of respondents came from participants from academia (35\%), followed by media (21\%), and then CSO/NGOs (18\%) (Figure 1). Survey respondents were purposively selected from a stakeholder list in tobacco control in Ghana.

\section{FINDINGS}

Seven key challenges/themes related to tobacco control in Ghana were identified (table 2).

- Lack of reliable data on use tobacco products.

- Affordability and availability of cigarettes.

- Strengthening tax administration and protecting public health policy from industry interference.

- Poor compliance to smoke-free policies and second hand smoke exposure.

- Improve sustainable funding of comprehensive programs on tobacco control in Ghana.

- Build institutional research capacity and establish a network for communicating information to stakeholders on relevant data and best practices. 
Table 2. Emerging themes from consultation on tobacco control in Ghana

\begin{tabular}{|c|c|}
\hline Themes & Research areas and notes \\
\hline $\begin{array}{l}\text { 1. Lack of reliable data on use of different tobacco } \\
\text { products in Ghana }\end{array}$ & $\begin{array}{l}\text { - To determine the prevalence and associated demographic and socioeco- } \\
\text { nomic factors of water pipe use among adults and young people. } \\
\text { - To understand the drivers of the use of tobacco products such as water pipe } \\
\text { among young people. } \\
\text { - To determine the impact of tobacco use among different age groups at the } \\
\text { regional level in Ghana. }\end{array}$ \\
\hline $\begin{array}{l}\text { 2. Affordability and availability of tobacco products } \\
\text { in Ghana }\end{array}$ & $\begin{array}{l}\text { - Generate country-specific data on the sale of single sticks, water pipe and } \\
\text { smokeless tobacco use at the regional level in Ghana }\end{array}$ \\
\hline $\begin{array}{l}\text { 3. Strengthening tax administration and protecting } \\
\text { public health policy from industry interference }\end{array}$ & $\begin{array}{l}\text { Extensive research into the magnitude and impact of tobacco industry in- } \\
\text { terference in public health policy. } \\
\text { 2. Generate data on tobacco taxation and the extent of illicit tobacco trade } \\
\text { in Ghana. }\end{array}$ \\
\hline $\begin{array}{l}\text { 4. Compliance to smoke-free policies and second } \\
\text { hand smoke exposure in Ghana }\end{array}$ & $\begin{array}{l}\text { - To evaluate the current smoke-free policy. } \\
\text { - Generate current objective data on second-hand smoke in public places in- } \\
\text { cluding hospitality venues. }\end{array}$ \\
\hline $\begin{array}{l}\text { 5. Improve sustainable funding of comprehensive } \\
\text { programs on tobacco control in Ghana }\end{array}$ & $\begin{array}{l}\text { - Institutional arrangements for promoting alternative crops (for tobacco } \\
\text { farmers), education, communication and training. } \\
\text { - Use of existing data by policy makers and governments in SSA and beyond } \\
\text { to inform the creation and implementation of projects that provide eco- } \\
\text { nomically viable alternatives for tobacco farmers. } \\
\text { - Comprehensive strategy to finance tobacco control on a sustainable basis } \\
\text { need to be emphasized. }\end{array}$ \\
\hline $\begin{array}{l}\text { 6. Build institutional research capacity and establish } \\
\text { a network for communicating information to } \\
\text { stakeholders on relevant data and best practices }\end{array}$ & $\begin{array}{l}\text { - Training investigators and strengthening links between basic, epidemiologi- } \\
\text { cal, clinical, and policy research, thus fostering a problem solving, multidisci- } \\
\text { plinary approach (as in the TCCP). } \\
\text { - Stronger stakeholder communication and engagement on tobacco control } \\
\text { to build capacity and trust with target communities and key stakeholders. }\end{array}$ \\
\hline 7. Social and behavioural change communication & $\begin{array}{l}\text { - Improve public awareness campaigns and school health programs including } \\
\text { risk communication and the incorporation of health effects of tobacco in } \\
\text { school curriculum. } \\
\text { - Health promotion methods such as awareness-raising campaigns can be or- } \\
\text { ganized in public spaces such as schools and use of the media (including so- } \\
\text { cial media) to promote a beneficial healthy and attractive non-smoking im- } \\
\text { age. }\end{array}$ \\
\hline
\end{tabular}

- Social and behavioural change communication.

\section{DISCUSSION}

This stakeholder consultation exercise enabled targeted feedback on research priorities and current gaps and challenges in tobacco control in Ghana. The results provide a valuable insight to both researchers and stakeholders, including policy makers to help direct the long-term development of their respective research portfolios. It also adds to the knowledge base regarding approaches to integrate evidence into policy and practice, and to build research capacity in low-resource settings.

Stakeholders in the meeting identified the lack of data on tobacco use and patterns of use as an important gap in tobacco control Ghana. In particular, the uptake and drivers of shisha (water pipe) use among young people was identified as an important research priority. This correlates with the increasing shisha use among young people in SSA and beyond. Despite tobacco use prevalence reducing in Ghana (GYTS 2000-2017) (table 1), shisha smoking among young people is becoming particularly common and fashionable. ${ }^{10}$
Studies have indicated that young people including adolescents are increasingly attracted to this smoking method, which acts as a precursor of future cigarette use. ${ }^{10}$ This has been attributed to the widespread public perception that shisha smoking is less harmful, and thus more socially acceptable, than cigarettes, despite exhibiting similar adverse health effects. ${ }^{14}$ Despite regulations on cigarettes and other tobacco products in Ghana, shisha's unique idiosyncrasies pose challenges to regulation. Several local, anecdotal reports suggest shisha legislation enactment and enforcement is dogged by unclear interpretation of the law and potential loopholes in Ghana and other SSA countries. Thus, a better understanding of the patterns and trends in tobacco use including shisha would help policy-makers in designing stronger, more targeted tobacco control policies and allocate adequate resources for implementing and supporting these policies.

Another key research priority is the strengthening of the tax administration and protecting public health policy from industry interference in Ghana. Tobacco industry interference has existed for years with the intention of subverting the role of governments and tobacco advocates implement- 
ing public health policies to combat the tobacco epidemic. ${ }^{15}$ Findings by the University of Bath indicates tobacco industry interference in the legislative processes of several African countries including Kenya, Rwanda, South Africa and Uganda. ${ }^{16}$ Stakeholders in the meeting also emphasized the interference by the tobacco industry in manipulating the legislative instrument on warning labels on cigarette packs and also interfering in the implementation of tobacco taxes in Ghana. According to the 2020 Global Tobacco Industry Interference Index, which scores countries on how well governments are resisting tobacco industry interference, Ghana stood at $20^{\text {th }}$ out of 57 countries $^{17}$ suggesting some level of interference by the industry. Also, the Tobacco Control Regulation (LI.2247) in Ghana lacks clarity on provisions made to regulate the interference of industry actors or participation of the tobacco industry in policy development. ${ }^{18}$ While there is some evidence (mainly anecdotal) of TI interference in tobacco control policy implementation in Ghana, the magnitude and impact of the interference is not well documented. ${ }^{12}$ There is little or no documentation on the implementation of Article 5.3 in Ghana and SSA, and where the implementation has happened there is no evidence on the impact and more so the nature, form and extent of influence. ${ }^{8}$

Another contributor to Ghana's tobacco control challenges is the sale of single sticks of cigarettes. ${ }^{19}$ Despite the ban of single stick sales since 2017, it continues to remain in many parts of Ghana particularly the Northern region, where smoking is prevalent among low-income groups. ${ }^{11}$ Single sticks offer a more affordable option to young people and other individuals particularly from low-income groups and undermine the smoker's intention to quit. The cost of a stick of cigarette is in Ghana 0.15 pesewas (USD 0.04) while a pack of 10 sticks costing GHS1.50p (USD 0.30). ${ }^{20}$ This calls for additional evidence to understand the drivers of single stick sales in Ghana and also consider licensing of retail vendors of tobacco products.

Single stick sales in Ghana also occur concomitantly with illicit tobacco. Stakeholders indicated the need to identify the drivers, nature, effects, magnitude, mitigation strategies for illicit tobacco trade in Ghana and SSA, which have largely been understudied. ${ }^{21}$ According to the Euromonitor, whose data is misleading, illicit trade volumes account for $24 \%$ of total volume sales in 2016 in Ghana. ${ }^{22}$ This has been linked to Ghana's porous borders and partly due to high excise duty in comparison to many regional countries. However, historical evidence shows that it was driven by tobacco industry involvement with cigarettes sourced from Burkina Faso and Nigeria. ${ }^{23}$ The North of Ghana particularly sees strong illicit trade, with most smuggling from Burkina Faso ending in this region. Given the rising tobacco epidemic, particularly among young people, the availability of an unregulated tobacco market (including sale of single sticks) and the lack of effective policies on illicit tobacco trade, it is timely to examine the current nature and extent of illicit tobacco trade in Ghana and to understand the tobacco industry's involvement in this trade.

Our consultation findings emphasized the importance of building institutional and individual research capacity as well as early and meaningful engagement of stakeholders in the research process to facilitate effective research. Its been documented that for research to have a positive effect in low-resource settings, research funding must be based on the country's needs and priorities. ${ }^{13}$ The results from the consultation support this position, calling for research funding to be based on country need, and to be designed and delivered by the stakeholders in the country of interest. However, the findings, including recommendations arising from this meeting must be considered in the context of several limitations. Stakeholders were limited in number and may not be representative of all of those relevant to tobacco control in Ghana. Also, there may be reluctance by stakeholders to openly express their opinions, especially criticisms, of present implementation, coordination, resources and achievements in a meeting where multiple organizations are present. Nevertheless, the selection strategy purposely sought to involve people from various national and regional level organizations and agencies with differing remits across the country in order to represent a wide range of perspectives and experiences.

\section{CONCLUSIONS AND FUTURE DIRECTIONS}

With over ten years into the WHO FCTC implementation, several countries in the African region (including Ghana) still have weak Tobacco Control Policy formulation, adoption and implementation. Therefore, it's imperative to conduct policy- and context-relevant tobacco research to strengthen existing policies and develop new policies and programs to curtail the harms of tobacco use. This stakeholder consultation exercise provided useful insights to funders, researchers and policy makers into emerging trends in tobacco control research in Ghana and SSA. GCRFTCCP is prepared to work with others to advocate for global tobacco control research and country-specific research ideas in addition to supporting the development of regional networks and policy relevant research in LMICs.

\section{ACKNOWLEDGMENTS}

We would like to acknowledge the contributions of all the key facilitators (particularly Dr. Paul Okyere) and representatives at the stakeholder consultation that informed the development of this manuscript. We are also grateful to the management and staff of the SPH-KNUST for hosting the event and providing all the technical support.

\section{FUNDING}

This research was completed as part of the Tobacco Control Capacity Programme. UKRI Global Challenges Research Fund (MR/P027946/2) supported this work.

\section{AUTHORSHIP CONTRIBUTIONS}

AS drafted the initial version of the manuscript. Fiona Dobbie, Fiona Davidson and LB contributed to the revision of the manuscript for important intellectual content and final approval. All other authors reviewed the final draft for approval. 


\section{COMPETING INTERESTS}

The authors completed the Unified Competing Interest form at www.icmje.org/coi_disclosure.pdf (available upon request from the corresponding author), and declare no conflicts of interest.

\section{CORRESPONDENCE TO:}

Dr Arti Singh
School of Public Health, KNUST,

Kumasi, Ghana.

Email: artisingh_uk@yahoo.com

Tel: $+233-244464576$

Submitted: January 11, 2021 GMT, Accepted: March 17, 2021

GMT 


\section{REFERENCES}

1. WHO. WHO Report on the Global Tobacco Epidemic, 2017. World Health Organization; 2017.

2. Gigliotti M, Schmidt-Traub G, Bastianoni S. The sustainable development goals. In: Encyclopedia of Ecology. Elsevier; 2018. https://doi.org/10.1016/B97 8-0-12-409548-9.10986-8

\section{World Health Organization. Noncommunicable} Diseases Progress Monitor 2015. WHO; 2015.

4. Wu F, Guo Y, Chaterji S, et al. Common risk factors for chronic non-communicable diseases among older adults in china, ghana, mexico, india, russia and south africa: The study on global AGEing and adult health (SAGE) wave 1. BMC Public Health. Published online 2015. doi:10.1186/s12889-015-1407-0

5. WHO. WHO Framework on Tobacco Control. World Health Organization; 2005.

6. Wellington E. Challenges of Implementation of the WHO Framework Convention on Tobacco Control (FCTC) - a case study of Ghana. Published online 2017.

7. Tumwine J. Implementation of the Framework Convention on Tobacco Control in Africa: Current status of legislation. International Journal of Environmental Research and Public Health. Published online 2011. doi:10.3390/ijerph8114312

8. Tobacco Atlas. Ghana Fact sheet. Published online 2017. Accessed January 2, 2021. https://tobaccoatlas.o rg/wp-content/uploads/pdf/ghana-country-facts.pdf.

9. WHO. Global Youth Tobacco Survey. Published online 2017.

10. Logo DD, Kyei-Fareid S, Oppong FB, et al. Waterpipe use among the youth in Ghana: Lessons from the Global Youth Tobacco Survey (GYTS) 2017. Tobacco Induced Diseases. Published online 2020. do i:10.18332/TID/120937

11. Yawson AE, Baddoo A, Hagan-Seneadza NA, et al. Tobacco use in older adults in Ghana:

Sociodemographic characteristics, health risks and subjective wellbeing. BMC Public Health. Published online 2013. doi:10.1186/1471-2458-13-979

12. Singh A, Owusu-Dabo E, Mdege N, McNeill A, Britton J, Bauld L. A situational analysis of tobacco control in Ghana: progress, opportunities and challenges. Journal of Global Health Reports. Published online 2020. doi:10.29392/001c.12260
13. Dobbie F, Mdege N, Davidson F, et al. Building capacity for applied research to reduce tobaccorelated harm in low- and middle-income countries: the Tobacco Control Capacity Programme (TCCP). Journal of Global Health Reports. Published online 2019. doi:10.29392/joghr.3.e2019055

14. FDA. Shisha is illegal in Ghana. Published online April 18, 2019. Accessed January 22, 2021. https://ww w.ghanaweb.com/GhanaHomePage/NewsArchive/Shis ha-is-illegal-in-Ghana-FDA-739656

15. Van Walbeek C, Filby S. Analysis of Article 6 (tax and price measures to reduce the demand for tobacco products) of the WHO Framework Convention on Tobacco Control. Tobacco Control. Published online 2019. doi:10.1136/tobaccocontrol-2018-054462

16. Gilmore AB, Fooks G, Drope J, Bialous SA, Jackson RR. Exposing and addressing tobacco industry conduct in low-income and middle-income countries. The Lancet. Published online 2015. doi:10.1016/S014 0-6736(15)60312-9

17. Tobacco Industry Interference in Ghana - STOP. Accessed March 14, 2021. https://exposetobacco.org/c ountry/ghana/

18. Ali I. Adoption of the Tobacco Control Regulations - Legislative Instrument (LI) 2247 to reduce the burden of NCDs and to advance WHO FCTC implementation in Ghana. Tobacco Induced Diseases. Published online 2018. doi:10.18332/tid/84145

19. Ghana Details. Tobacco Control Laws. Accessed February 2, 2021. https://www.tobaccocontrollaws.or g/legislation/country/ghana/summary

20. Ghana Web. 5,000 Ghanaian children between 10-14 years smoke - VALD. Accessed February 2, 2021. https://www.ghanaweb.com/GhanaHomePage/ NewsArchive/5-000-Ghanaian-children-between-1 0-14-years-smoke-VALD-967423

21. walbeek C, Blecher E, Gilmore A, Ross H. Price and tax measures and illicit trade in the framework convention on tobacco control: What we know and what research is required. Nicotine and Tobacco Research. Published online 2013. doi:10.1093/ntr/nts1 $\underline{70}$

22. EuromonitorInternational. Euromonitor International - Analysis. Published online 2015.

23. Drope J. Tobacco Control in Africa: People, Politics and Policies. Anthem Press; 2011. doi:10.7135/UPO97 80857288134 